\title{
A Geometry Effect of Carbon Nanomaterials on Flame Retardancy and Mechanical Properties of Ethylene-Vinyl Acetate/Magnesium Hydroxide Composites
}

\author{
Zhi-Qi Liu ${ }^{1,2,3}$, Zhi Li ${ }^{3,4}$, Yun-Xian Yang ${ }^{3}$, Yan-Ling Zhang ${ }^{1,2}$, Xin Wen ${ }^{3,5}, \mathrm{Na} \mathrm{Li}^{1,2,6}$, \\ Can Fu ${ }^{3,4}$, Rong-Kun Jian ${ }^{3,7}$, Li-Juan Li ${ }^{1,2}$ and De-Yi Wang ${ }^{3, *}$ \\ 1 Key Laboratory of Comprehensive and Highly Efficient Utilization of Salt Lake Resources, \\ Qinghai Institute of Salt Lakes, Chinese Academy of Sciences, Xining 810008, China; \\ zqliu@isl.ac.cn (Z.-Q.L.); ylzhang@isl.ac.cn (Y.-L.Z.); lina162@mails.ucas.ac.cn (N.L.); lilj@isl.ac.cn (L.-J.L.) \\ 2 Qinghai Engineering and Technology Research Center of Comprehensive Utilization of Salt Lake Resources, \\ Xining 810008, China \\ 3 IMDEA Materials Institute, C/Eric Kandel, 2, 28906 Getafe, Spain; zhi.li@imdea.org (Z.L.); \\ yunxian.yang@imdea.org (Y.-X.Y.); hgwenxin@126.com (X.W.); can.fu@imdea.org (C.F.); \\ jrkht1987@fjnu.edu.cn (R.-K.J.) \\ 4 Universidad Politécnica de Madrid, E.T.S. de Ingenieros de Caminos, Madrid 28040, Spain \\ 5 Nanomaterials Physicochemistry Department, Faculty of Chemical Technology and Engineering, West \\ Pomeranian University of Technology in Szczecin, 70-311 Szczecin, Poland \\ 6 University of Chinese Academy of Sciences, Beijing 100049, China \\ 7 Fujian Provincial Key Laboratory of Polymer Materials, College of Chemistry and Materials \\ Science, Fujian Normal University, Fuzhou 350007, China \\ * Correspondence: deyi.wang@imdea.org; Tel.: +34-91-549-3422
}

Received: 30 August 2018; Accepted: 12 September 2018; Published: 14 September 2018

\begin{abstract}
This study was aimed at investigating the effects of carbon nanomaterials with different geometries on improving the flame retardancy of magnesium hydroxide-filled ethylene-vinyl acetate (EM). The thermal stability and flame retardancy were studied by thermogravimetric analysis (TGA), limiting oxygen index (LOI), UL-94 test, and cone calorimeter test (CCT). The in situ temperature monitoring system and interrupted combustion offered direct evidence to link flame retardancy and composite structure. Results demonstrated that carbon nanomaterials enhanced the thermal stability and fire safety of EM. The geometry of carbon nanomaterials played a key role in synergistic flame retardancy of EM, with the flame-retardant order of carbon nanotube $>$ nanoscale carbon black $>$ graphene. Based on an online temperature monitoring system and interrupted combustion test, one-dimensional carbon nanotube was more inclined to form the network structure synergistically with magnesium hydroxide in ethylene-vinyl acetate, which facilitated the generation of more continuous char structure during combustion. In parallel, the mechanical property was characterized by a tensile test and dynamic mechanical analysis (DMA). The incorporation of carbon nanomaterials presented a limited effect on the mechanical properties of the EM system.
\end{abstract}

Keywords: ethylene-vinyl acetate; magnesium hydroxide; carbon material; flame retardant

\section{Introduction}

Ethylene-vinyl acetate (EVA) is a typical thermoplastic elastomer that is extensively applied in hot-melt adhesive, flexible pipe, battery adhesive film or toys, and especially in the cable industry as an excellent insulating material with good physical and mechanical properties [1]. However, EVA can 
be ignited easily and burns very rapidly, producing enormous heat and toxic gas. Even under an oxygen-deficient environment, combustion is sustained with the generation of melt dripping, which restricts its practical applications [2]. One of the most effective ways to overcome this drawback is to add flame retardants to EVA, and recently much research is focused on the use of environmentally friendly halogen-free flame-retardant (HFFR) additives [3].

As an HFFR filler, magnesium hydroxide (MH) is extensively used to prepare flame-retardant composites, because of its good smoke suppression and high thermal decomposition temperature $[4,5]$. There have been many reports about $\mathrm{MH}$ applications in polymers, such as polyvinyl chloride (PVC) [6], polypropylene (PP) [7], polyethylene (PE) [8], epoxy resin [9], etc. However, it has a serious disadvantage of low flame-retardant efficiency, and it commonly requires more than $50 \mathrm{wt} \%$ MH to meet flame-retardancy of polymers, which inevitably results in the deterioration of physical and mechanical properties of polymers. Therefore, various studies have been done to enhance the flame retardancy and decrease the loading of $\mathrm{MH}$ by combining $\mathrm{MH}$ with other synergistic additives, such as silica [1], red phosphorous [10], hollow glass microsphere [4], zinc borate [11], clay [12,13], layered double hydroxide [14], etc.

To date, carbon nanomaterials with high thermal conductivity, high strength, flexibility, and low density have attracted considerable attention for developing high-performance polymer composites [15-19]. Interestingly, except for the strengthening effect, the incorporation of carbon nanomaterials is also found to improve the flame retardancy of polymers. Dittrich et al. [20] reported that the peak heat release rate (PHRR) of composites with $1 \%$ multiwall carbon nanotubes (CNs) was reduced by about $73 \%$ compared to that of PP. Wen and Yang et al. [21,22] revealed that nanocarbon black (CB) could increase the thermal stability and flame retardancy of polyolefin due to its trapping radical effect during the burning of composites. Graphene (CG) has attracted tremendous attention and research interest in the scientific community [23,24]. Liu et al. [25] reported that after pristine graphene or graphene oxide was incorporated into thermosetting resins, the PHRR of composites displayed a decreasing trend compared with pure epoxy resin. Based on the above studies, it is clear that $\mathrm{CB}, \mathrm{CN}$, and $C G$ all have a positive effect on improving the flame retardancy of polymers. It is known that the three carbon nanomaterials have different geometries: $\mathrm{CB}$ is considered to be a zero-dimension structure, $\mathrm{CN}$ is regarded as a one-dimension structure, and CG is a two-dimension structure; thus it is worth investigating whether they have different behaviors in flame-retarding polymers. To the best of our knowledge, there is little work on this, and it is meaningful to explore the flame-retardant behaviors of $\mathrm{CB}, \mathrm{CN}$, and CG in magnesium hydroxide-filled EVA.

In order to insightfully investigate the effect of carbon nanomaterials with different geometries on improving the flame retardancy of magnesium hydroxide-filled ethylene-vinyl acetate matrix (EM), $\mathrm{CB}, \mathrm{CN}$, and CG were chosen. In this work, the influence of these carbon materials on thermal stability, burning behavior, synergistic interaction, and mechanical properties of EVA/MH composites was also investigated.

\section{Experimental}

\subsection{Materials}

Ethylene-vinyl acetate (EVA) copolymer (Elvax-265, containing 28 wt \% vinyl acetate) was supplied by DuPont Company (Wilmington, DE, USA). Magnesium hydroxide (MAGNIFIN H-5, with a content of $\mathrm{MH}$ more than 99.8\%) was provided by Albemarle Corporation (Charlotte, NC, USA). Carbon black (particle diameter of $17 \mathrm{~nm}$, purity > 99\%) was purchased from Linzi Qishun Chemical Co. (Zibo, China). Carbon nanotube (10-30 nm, purity >99\%) was supplied by Chengdu Organic Chemicals Co. Ltd., Chinese Academy of Sciences (Chengdu, China). Graphite (325 mesh, purity $>99 \%$ ) was purchased from Nanjing JCNANO Technology Co., Ltd. (Nanjing, China). AR grade sulfuric acid, potassium permanganate, hydrogen peroxide, and barium chloride were supplied by Tianjin Kemiou Chemical Reagent Co., Ltd. (Tianjin, China). 


\subsection{Preparation of Graphene}

Graphene was prepared by the oxidation of natural graphite powder according to Hummers' method [26-28]. First, a beaker with $70 \mathrm{~mL} \mathrm{H}_{2} \mathrm{SO}_{4}$ liquid was put in an ice bath and 3.0 g graphite powder was added to the liquid under stirring. Successively, $9.0 \mathrm{~g} \mathrm{KMnO}_{4}$ was slowly added to the suspension solution with the temperature lower than $20^{\circ} \mathrm{C}$ for $2 \mathrm{~h}$. Then, the suspension solution was transferred to an oil bath at $40{ }^{\circ} \mathrm{C}$, stirring continuously for $0.5 \mathrm{~h}$. A further $150 \mathrm{~mL}$ water was added into the solution and heated to $90^{\circ} \mathrm{C}$. The solution was stirred for $15 \mathrm{~min}$ and an additional $500 \mathrm{~mL}$ water was added. After that, $15 \mathrm{~mL} \mathrm{H}_{2} \mathrm{O}_{2}$ was slowly added to the solution until the color changed from dark brown to yellow. Finally, the solution was filtered and washed with $1 / 10 \mathrm{HCl}$ aqueous solution until sulfate radical was not detected by barium chloride solution. The filter cake was dried in the air and screened by 325 standard mesh.

\subsection{Preparation of EVA Composites}

All EVA compounds with carbon fillers of variable sizes and geometries were processed under identical conditions using a micro compounder (MC-15, Xplore Instruments BV, Sittard, the Netherlands). Processing of the composites was carried out at a temperature of $180{ }^{\circ} \mathrm{C}$ with a screw speed of $50 \mathrm{rpm}$ and time of $15 \mathrm{~min}$. The samples for the flame test and mechanical property test were obtained by using a hot press. All the samples were dried in a vacuum oven at $80^{\circ} \mathrm{C}$ for $2 \mathrm{~h}$ before processing. The formulations are given in Table 1 , and the corresponding materials were named magnesium hydroxide-filled EVA (EM), magnesium hydroxide-filled EVA/carbon black (EMCB), magnesium hydroxide-filled EVA/carbon nanotube (EMCN), and magnesium hydroxide-filled EVA/grapheme (EMCG).

Table 1. Formulations of ethylene-vinyl acetate (EVA) composites.

\begin{tabular}{cccccc}
\hline Sample & EVA (wt \%) & MH (wt \%) & CB (wt \%) & CN (wt \%) & CG (wt \%) \\
\hline EVA & 100 & 0 & 0 & 0 & 0 \\
EM & 50 & 50 & 0 & 0 & 0 \\
EMCB & 50 & 49 & 1 & 0 & 0 \\
EMCN & 50 & 49 & 0 & 1 & 0 \\
EMCG & 50 & 49 & 0 & 0 & 1
\end{tabular}

$\mathrm{MH}$, magnesium hydroxide; $\mathrm{CB}$, nanocarbon black; $\mathrm{CN}$, carbon nanotube; $\mathrm{CG}$, graphene; $\mathrm{EM}$, magnesium hydroxide-filled EVA; EMCB, magnesium hydroxide-filled EVA/carbon black; EMCN, magnesium hydroxide-filled EVA/carbon nanotube; EMCG, magnesium hydroxide-filled EVA/grapheme.

\subsection{Characterization and Measurement}

Thermogravimetric analysis (TGA) was performed with a TA thermogravimetric analyzer (Q50, New Castle, PA, USA) from 50 to $600^{\circ} \mathrm{C}$, with a heating rate of $10^{\circ} \mathrm{C} / \mathrm{min}$ in nitrogen atmosphere. Limiting oxygen index (LOI) was obtained using an oxygen index meter (FTT, East Grinstead, UK) according to American Society for Testing and Materials (ASTM) D2863-77 standard. The size of the samples was $130 \times 6.5 \times 3 \mathrm{~mm}^{3}$.

The vertical burning test was determined with the UL-94 vertical flame chamber (FTT, East Grinstead, UK) according to ASTM D3801 standard. The size of the samples was $130 \times 13 \times 3 \mathrm{~mm}^{3}$.

The fire behavior of the samples was determined on a cone calorimeter (FTT, East Grinstead, UK) according to the ISO5660 standard, under a heat flux of $50 \mathrm{~kW} / \mathrm{m}^{2}$ with a sample size of $100 \times 100 \times 3 \mathrm{~mm}^{3}$. The temperature detection was carried out during the cone calorimeter test (CCT) with K-type thermocouple. The sample temperatures at the middle and bottom layers during combustion were monitored. The middle and bottom thermocouples were fixed by the premade hole and sample holder, respectively. Figure 1 shows the experimental setup for cone calorimeter tests and temperature measurements. 


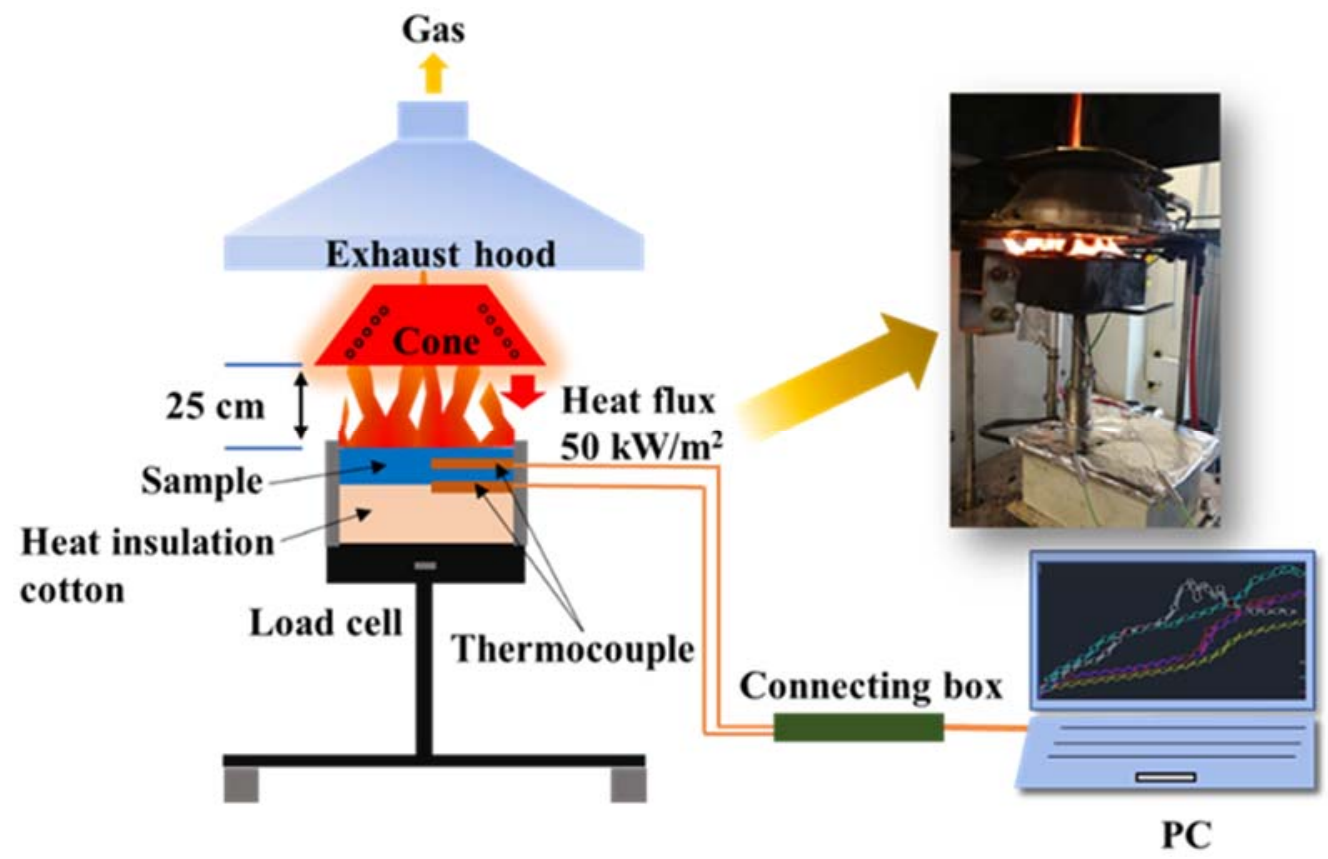

Figure 1. Schematic of experimental setup used for temperature measurements.

The dispersion state of different fillers in EVA matrix were examined with a scanning electron microscope (Helios NanoLab 600i, FEI, Portland, OR, USA). The samples were fractured in liquid nitrogen, and the fracture surfaces were coated with gold before SEM observation.

Tensile testing was performed on a universal electromechanical testing machine (INSTRON 3384, Norwood, MA, USA) according to ASTM D 638 standard at a test speed of $50 \mathrm{~mm} / \mathrm{min}$.

Dynamic mechanical properties were measured by a DMA Q800 (TA Instruments, New Castle, PA, USA). The dynamic storage modulus was determined at a frequency of $1 \mathrm{HZ}$ and a heating rate of $3^{\circ} \mathrm{C} / \mathrm{min}$ between -50 and $50{ }^{\circ} \mathrm{C}$.

\section{Results and Discussion}

\subsection{Thermal Stability}

The thermal stability of EVA and its composites with MH and carbon materials was investigated by TGA in nitrogen atmosphere. The TGA and derivative thermogravimetry (DTG) curves of neat EVA and its nanocomposites are plotted in Figure 2, and the corresponding data are listed in Table 2. It was observed that all samples exhibited a distinct two-step decomposition process. The first stage was due to the loss of acetic acid in EVA and the dehydration of $\mathrm{MH}$ from 300 to $400{ }^{\circ} \mathrm{C}$. The second stage involved volatilization of the residual polymer and degradation of ethylene-based chains $[29,30]$. As shown in Figure 2, the pure EVA maximum weight-loss temperature $\left(T_{\max 1}\right.$ and $\left.T_{\max 2}\right)$ for the two decomposition steps was 348 and $428^{\circ} \mathrm{C}$, respectively. Compared with the pure EVA and EM, EM with carbon nanomaterials had a higher initial decomposition temperature $\left(T_{-5}\right)$ and $T_{\max 1}$ because carbon nanomaterials are highly thermal stable; besides, all char yields had a slight increase, which was higher than $34.5 \mathrm{wt} \%$ of EM, indicating that carbon nanomaterials were beneficial in promoting char formation. It should be noted that the thermal stability of EMCB, EMCN, and EMCG EMCN was improved, because the $\mathrm{MH}$ with numerous interconnection carbon materials acted as a barrier, hindering the transport of degradation products and promoting the formation of stable charred layers [31]. 


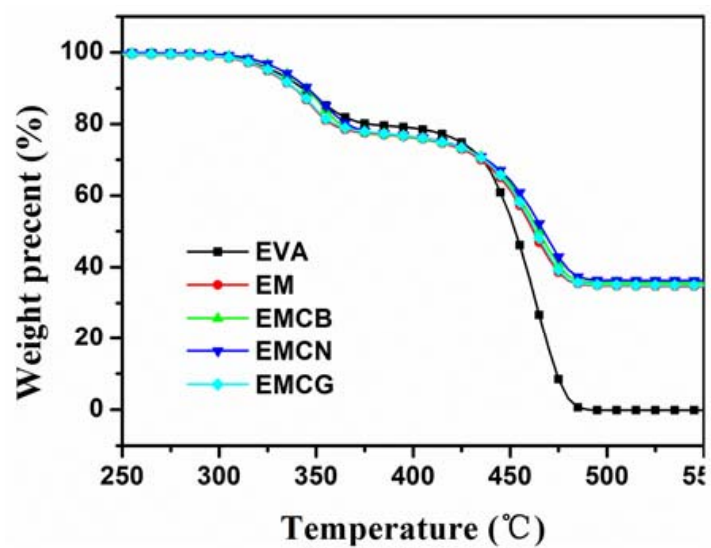

(a)

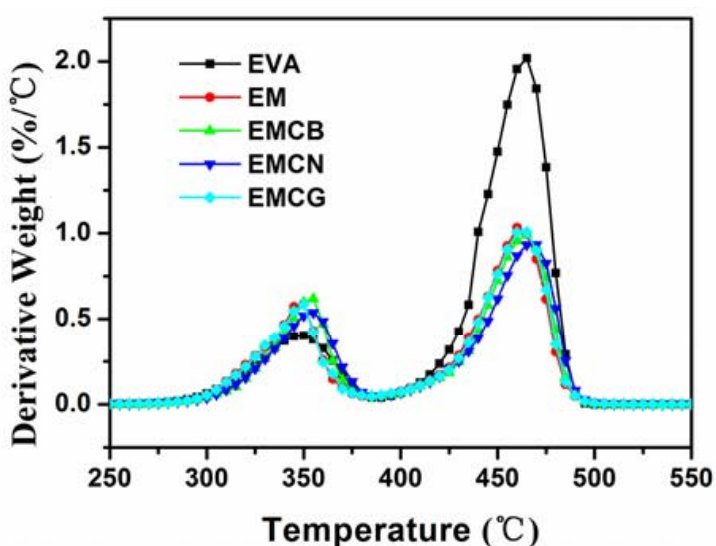

(b)

Figure 2. (a) TGA and (b) DTG curves of pure EVA and its composites at a heating rate of $10{ }^{\circ} \mathrm{C} / \mathrm{min}$ in nitrogen.

Table 2. TGA and DTG data of pure EVA and its composites in nitrogen.

\begin{tabular}{cccccc}
\hline Sample & $\boldsymbol{T}_{\boldsymbol{- 5} \mathbf{5}}{ }^{\mathbf{a}}\left({ }^{\circ} \mathbf{C}\right)$ & $\boldsymbol{T}_{-\mathbf{5 0} \%}{ }^{\mathbf{b}}\left({ }^{\circ} \mathbf{C}\right)$ & $\boldsymbol{T}_{\max \mathbf{1}}{ }^{\mathbf{c}}\left({ }^{\circ} \mathbf{C}\right)$ & $\boldsymbol{T}_{\boldsymbol{m a x} 2}{ }^{\mathbf{d}}\left({ }^{\circ} \mathbf{C}\right)$ & Char $^{\mathbf{e}} \mathbf{( \% )}$ \\
\hline EVA & 327 & 452 & 348 & 466 & 0 \\
EM & 324 & 462 & 348 & 461 & 34.5 \\
EMCB & 331 & 464 & 353 & 464 & 35.5 \\
EMCN & 332 & 467 & 354 & 468 & 36.1 \\
EMCG & 325 & 463 & 349 & 463 & 35.0 \\
\hline
\end{tabular}

a Temperature at $5 \mathrm{wt} \%$ weight loss. ${ }^{\mathrm{b}}$ Temperature at $50 \mathrm{wt} \%$ weight loss. ${ }^{\mathrm{c}}$ Temperature at first maximum mass loss rate. ${ }^{\mathrm{d}}$ Temperature at second maximum mass loss rate. ${ }^{\mathrm{e}}$ Residue at $600{ }^{\circ} \mathrm{C}$.

\subsection{LOI and UL-94}

The effect of $\mathrm{MH}$ and different carbon materials on the flammability of EVA was studied by limiting oxygen index (LOI) and UL-94 vertical burning test (Table 3). Digital photos of EVA composites after UL-94 test are displayed in Figure 3. It can be seen in Table 3 that the LOI value of pure EVA was only $18.5 \%$ and it failed to pass UL-94 rating. When $50 \mathrm{wt} \% \mathrm{MH}$ was added, the LOI value of EM increased to $25.8 \%$ and EM got a UL-94 V-1 rating. After $1 \mathrm{wt} \%$ carbon nanomaterials was added to the EM system, all of the EM composites with carbon materials passed UL-94 V-0 rating, and the LOI values of EMCB, EMCN, and EMCG further increased to $28.2 \%, 33.3 \%$, and $27.6 \%$, respectively. It can be seen that the LOI value of EMCN was the highest among EM with carbon nanomaterials and increased by $80 \%$ in comparison to pure EVA and $29 \%$ in comparison to EM. Figure 4 shows that EVA had significant melting and dripping, and EM had a little dripping and presented better flame-retardant performance than EVA, while the EM with carbon nanomaterials kept the original shape and had no dripping during UL-94 testing, indicating that the addition of carbon nanomaterials might enhance the melt viscosity of the matrix. All in all, it was concluded that all three carbon nanomaterials were beneficial in improving the flame-retardant efficiency of MH in EVA matrix, which was in the order of $\mathrm{CN}>\mathrm{CB}>\mathrm{CG}$. 
Table 3. Limiting oxygen index (LOI) and UL-94 results.

\begin{tabular}{ccccccc}
\hline \multirow{2}{*}{ Samples } & \multirow{2}{*}{ LOI (\%) } & \multicolumn{6}{c}{ UL-94 } \\
\cline { 3 - 7 } & & $\boldsymbol{t}_{\mathbf{1}}(\mathbf{s})$ & $\boldsymbol{t}_{\mathbf{2}}(\mathbf{s})$ & Dripping & Igniting the Cotton & Rating \\
\hline EVA & $18.5 \pm 0.2$ & $/$ & $/$ & Yes & Yes & Fail \\
EM & $25.8 \pm 0.2$ & 2 & 9 & Yes & No & V-1 \\
EMCB & $28.2 \pm 0.2$ & 1 & 2 & No & No & V-0 \\
EMCN & $33.3 \pm 0.2$ & 1 & 1 & No & No & V-0 \\
EMCG & $27.6 \pm 0.2$ & 1 & 3 & No & No & V-0 \\
\hline
\end{tabular}

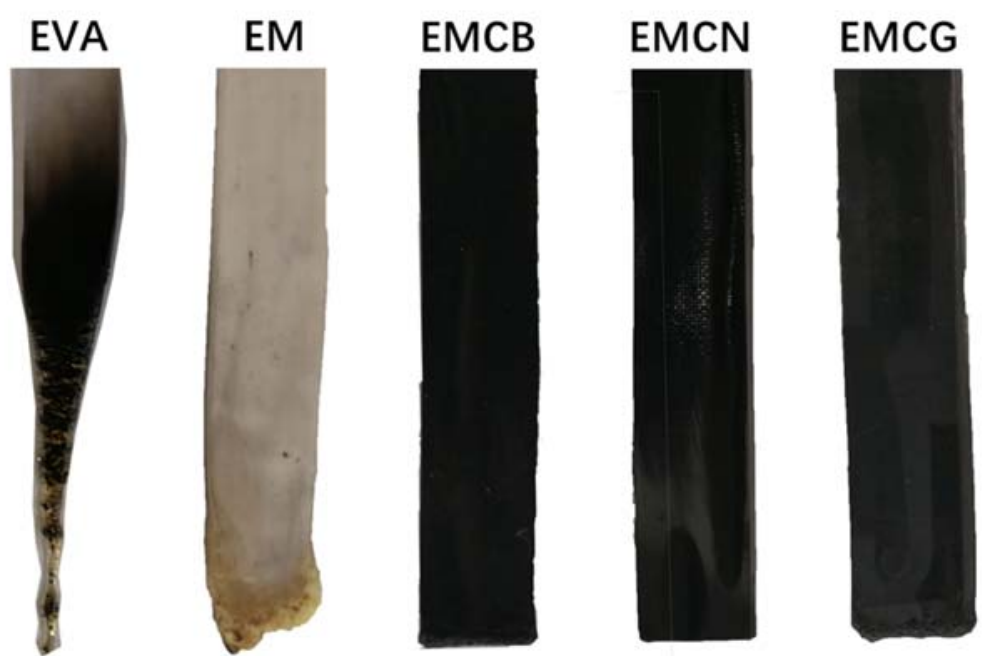

Figure 3. Digital photos of EVA composites after UL-94 tests.

\subsection{Cone Calorimeter Test}

Cone calorimetry is an effective method to study the combustion behavior of polymers [32,33], and was adopted to assess the fire performance of EVA and EVA-based composites. The related combustion data, including heat release rate (HRR), total heat release (THR), smoke production rate (SPR), total smoke production (TSP), and residue, are summarized in Table 4, and the curves of HRR and SPR versus time for EVA and its composites are presented in Figures 4 and 5.

Table 4. Combustion parameters obtained from cone calorimetry test.

\begin{tabular}{ccccccc}
\hline Sample & $\boldsymbol{t}_{\text {ign }} \mathbf{( s )}$ & PHRR $\left(\mathbf{k W} / \mathbf{m}^{\mathbf{2}}\right)$ & THR $\left(\mathbf{M J} / \mathbf{m}^{\mathbf{2}}\right)$ & SPR $\left(\mathbf{m}^{\mathbf{2}} / \mathbf{s}\right)$ & TSP $\left(\mathbf{m}^{\mathbf{2}} \mathbf{k g}\right)$ & esidue $(\mathbf{w t} \mathbf{\%})$ \\
\hline EVA & $36 \pm 2$ & $1139 \pm 50$ & $110 \pm 5$ & $0.084 \pm 0.004$ & $10.0 \pm 0.5$ & 0.0 \\
EM & $66 \pm 2$ & $536 \pm 20$ & $85 \pm 5$ & $0.058 \pm 0.002$ & $5.9 \pm 0.2$ & $40.4 \pm 1.0$ \\
EMCB & $55 \pm 1$ & $506 \pm 20$ & $84 \pm 5$ & $0.052 \pm 0.002$ & $5.3 \pm 0.2$ & $41.6 \pm 1.5$ \\
EMCN & $50 \pm 2$ & $308 \pm 15$ & $83 \pm 4$ & $0.029 \pm 0.001$ & $6.4 \pm 0.3$ & $48.7 \pm 2.0$ \\
EMCG & $54 \pm 1$ & $564 \pm 20$ & $82 \pm 4$ & $0.053 \pm 0.002$ & $5.5 \pm 0.2$ & $42.9 \pm 1.0$ \\
\hline
\end{tabular}

From Figure 4, it can be seen that the pure EVA was easily flammable after ignition, exhibiting a sharp peak in the HRR curve at $125 \mathrm{~s}$, with peak value at $1139 \mathrm{~kW} / \mathrm{m}^{2}$. When $50 \mathrm{wt} \% \mathrm{MH}$ was added to EVA, the PHRR of EM decreased remarkably from $1139 \mathrm{~kW} / \mathrm{m}^{2}$ of EVA to $536 \mathrm{~kW} / \mathrm{m}^{2}$, corresponding to a 53\% reduction compared to pure EVA. After carbon nanomaterials were added into the EM system, the EM with carbon samples burned more slowly than pure EVA and EM. Furthermore, compared with pure EVA, EMCB, EMCN, and EMCG composites, the peak of HRR curves decreased from 1139 to 506,308 , and $564 \mathrm{~kW} / \mathrm{m}^{2}$, respectively. The PHRR of EMCN was $305 \mathrm{~kW} / \mathrm{m}^{2}$, corresponding to a $73 \%$ reduction compared to pure EVA and 20\% reduction compared to EM. It can also be observed from Figure 4 that pure EVA burned very fast after ignition. The second sharp HRR curve appeared near $125 \mathrm{~s}$. For the sample with $\mathrm{MH}$, its second HRR was delayed to $210 \mathrm{~s}$. With the addition of 
$1 \mathrm{wt} \% \mathrm{CB}$ and CG in EM, the time of appearance of the second HRR remained nearly unchanged. However, in the EMCN sample with $1.0 \mathrm{wt} \% \mathrm{CN}$, its second HRR was lower than the first peak and was prolonged to $295 \mathrm{~s}$. The HRR of all of flame-retardant samples with carbon materials showed flat progress during burning, which indicates that the carbon materials facilitated the formation of a protective char layer. As a result, the combustion was suppressed. Lower HRR value is crucial for saving lives and assets during a fire. Compared with CB and CG, CN showed better flame-retardant efficiency with MH in EVA matrix.

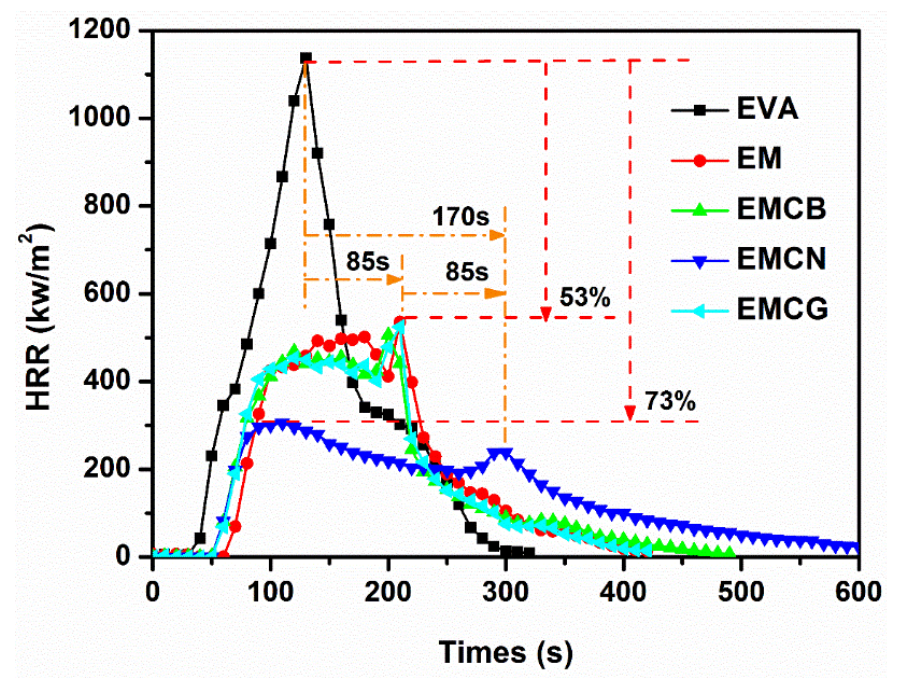

Figure 4. Heat release rate curves of EVA and its composites measured by a cone calorimeter at an external radiant flux of $50 \mathrm{~kW} / \mathrm{m}^{2}$.

The smoke performance of flame-retardant material is a very important parameter [34]. The SPR values of EVA and EVA-based composites are illustrated in Figure 5. It was seen that EVA had a high peak SPR value of $0.084 \mathrm{~m}^{2} / \mathrm{s}$. With the addition of $50 \mathrm{wt} \% \mathrm{MH}$, the peak SPR value of EM decreased dramatically to $0.058 \mathrm{~m}^{2} / \mathrm{s}$, corresponding to a $31 \%$ reduction compared to pure EVA, while in the presence of carbon nanomaterials, the peak SPR values of EMCB, EMCN, and EMCG composites further decreased from $0.058 \mathrm{~m}^{2} / \mathrm{s}$ of EM to $0.053,0.029$, and $0.052 \mathrm{~m}^{2} / \mathrm{s}$, respectively. The results indicate that $\mathrm{CN}$ gave rise to the best suppression effect on the smoke production of EM compared with CB and CG.

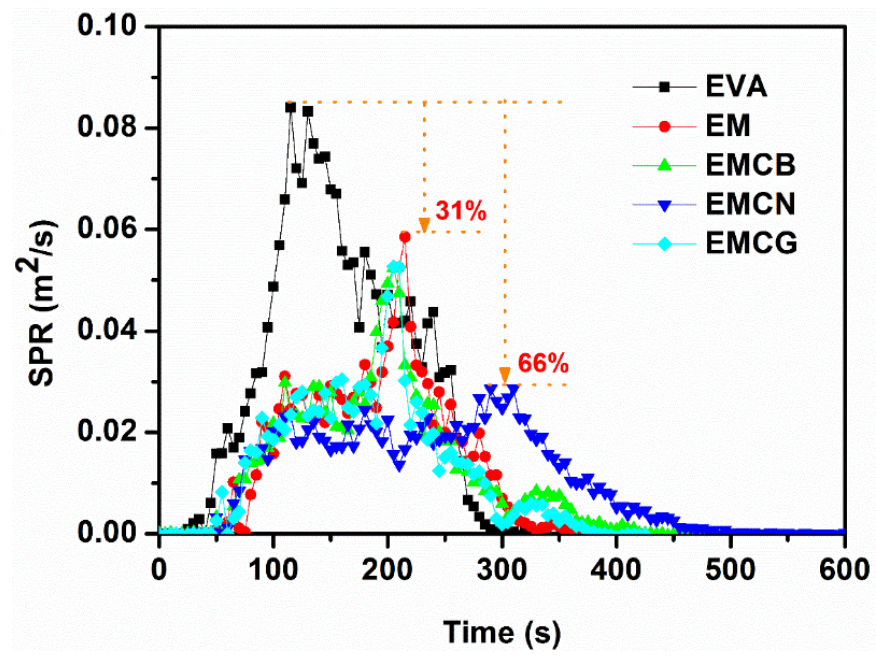

Figure 5. Smoke production rate of EVA and its composites measured by cone calorimeter at an external radiant flux of $50 \mathrm{~kW} / \mathrm{m}^{2}$. 


\subsection{Flame-Retardant Mechanism}

According to the above results, it was confirmed that the flame-retardant efficiency of $\mathrm{CB}, \mathrm{CN}$, and CG was very different, especially for $\mathrm{CN}$, and that $\mathrm{CN}$ showed the best synergistic effect with $\mathrm{MH}$ on flame-retarding EVA matrix. In order to investigate the flame-retardancy mechanism, an online temperature monitor with thermocouples placed in the middle and bottom of the specimen was adopted to monitor the real-time temperature during combustion, and the curves of temperature versus time for EVA and EVA-based composites are recorded in Figure 6. Interrupted combustion tests were also performed, together with a visual analysis of cross-sections of fire residues. According to the time of PHRR of EVA, interrupted combustion happened $125 \mathrm{~s}$ after the start of burning. Pictures of residues and cross-section pictures of residue obtained by interrupted combustion are shown in Figure 7.

As shown in Figure $6 \mathrm{a}$, the middle of the thermocouple detected the approximately similar increase in temperature for EVA and the EM composite. The EMCB and EMCG composites showed similar and nonsignificant differences during combustion. It is worth noticing that the temperature curve of EMCN was lower than other curves after approximately $50 \mathrm{~s}$ of burning. This was because the barrier layer had not formed on top of the specimen, and it did not effectively block the heat transfer at the initial combustion stage. In Figure $6 b$, it can be seen that the increased temperature rate of EVA was higher than that of EVA composites after approximately $50 \mathrm{~s}$; EM, EMCB, and EMCG temperature curves coincided during burning; and the EMCN temperature curve appeared lower after approximately $125 \mathrm{~s}$. With the development of the combustion process, a heat barrier was formed by $\mathrm{MH}$ and carbon materials. Consequently, the char layer had a stronger and stronger effect on combustion and delayed the temperature increase in the deeper parts of the specimen. Compared to EM, EMCB, and EMCG, the char of EMCN presented a better barrier effect. Based on the above cone calorimeter test results of residue, the better barrier effect of the residue mass was stronger than other samples.

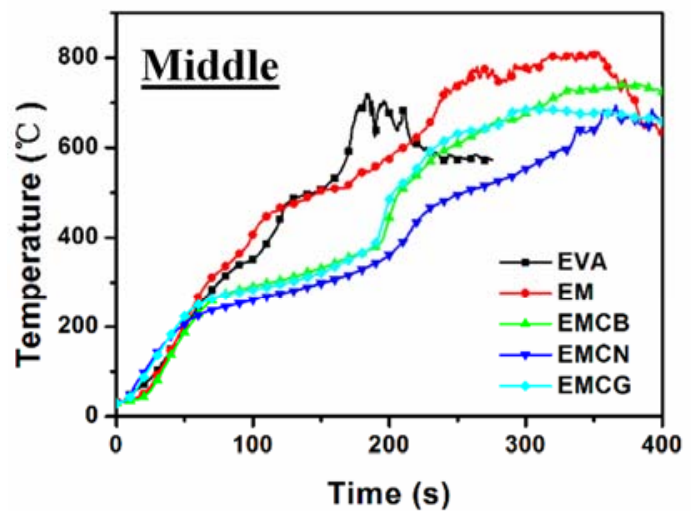

(a)

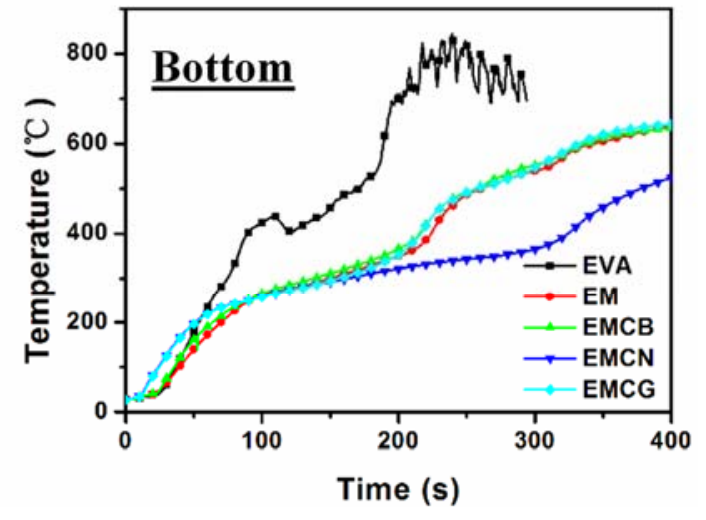

(b)

Figure 6. Temperature of specimens versus time for pure EVA and its nanocomposites: (a) middle temperature of specimen, and (b) bottom temperature of specimen.

As seen in Figure 7a, the EM composite cross-sections show the presence of voids originated by fuel bubbles in the whole thickness of the polymer, and a few plate-like chars appeared on the surface and did not cover the sample entirely. This indicates that the addition of MH into EVA matrix did not generate the obvious flame-retardant layer to prevent heat transport from flame into the materials. In Figure $7 \mathrm{~b}-\mathrm{d}$, a similar fuel bubble feature can be observed in the cross-section of the composites. However, after adding carbon materials at $1.0 \mathrm{wt} \%$ concentration to EVA and MH system, a layer of char appeared on top of the samples, indicating that the addition of carbon nanomaterials obviously increased the char residue of EM composite. 

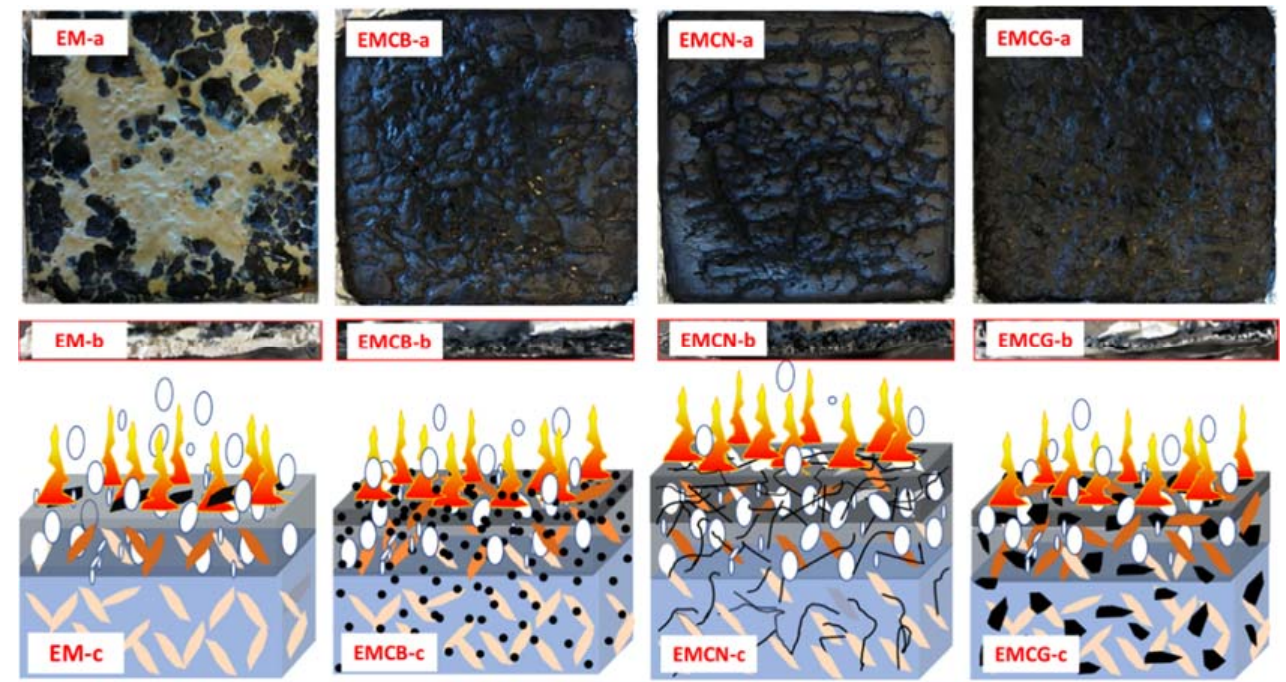

Figure 7. Cross-section pictures of residue obtained by interrupted irradiation and combustion diagram under cone calorimeter at 125 s. (a) upper surface; (b) cross-section; (c) combustion schematic diagram.

Takashi et al. demonstrated that the formation of a network structure of nanoparticles within a polymer matrix can significantly reduce nanocomposite flammability, and that viscoelastic properties could be utilized to predict that reduction $[31,35,36]$. The torque of the melting polymer is associated with melt viscosity and is extensively used to characterize the evolution of the polymer mixing process [37,38]. Figure 8 shows the applied torque of EVA with different fillers after mixing for $15 \mathrm{~min}$ at $180^{\circ} \mathrm{C}$ an average of nine times. The torque force value of pure EVA was $3200 \mathrm{~N}$; after the addition of $\mathrm{MH}$, the value increased to $5850 \mathrm{~N}$. This indicates that the filler of $\mathrm{MH}$ can remarkably increase the viscosity of EM composite. Three carbon materials were added into the EM system, and the value of force presents different results. Compared to EM, the value of EMCN slightly increased, EMCN obviously increased, and EMCG reduced. Because CB has much smaller particles than $\mathrm{MH}$, it cannot obviously influence the viscosity of EM composite. The reduction in EMCG was due to the layered structure of graphene, which had a lubrication effect in the processing of EVA. The increase of EMCN was attributed to the presence of long carbon nanotubes and the formation of network structures with polymer matrix in the nanocomposites. It is worth noticing that the EMCN composite presented better flame-retardant performance than other composites due to the formed network [31,36]; the high melt viscosity reduced the bubble rise rate and bubble growth rate of volatile degradation products. This EMCN structure greatly increased the thickness and integrity of the charred layer, acted as a heat insulator, limited the emission of volatile thermal degradation products, and thus improved the thermal oxidative stability [38].

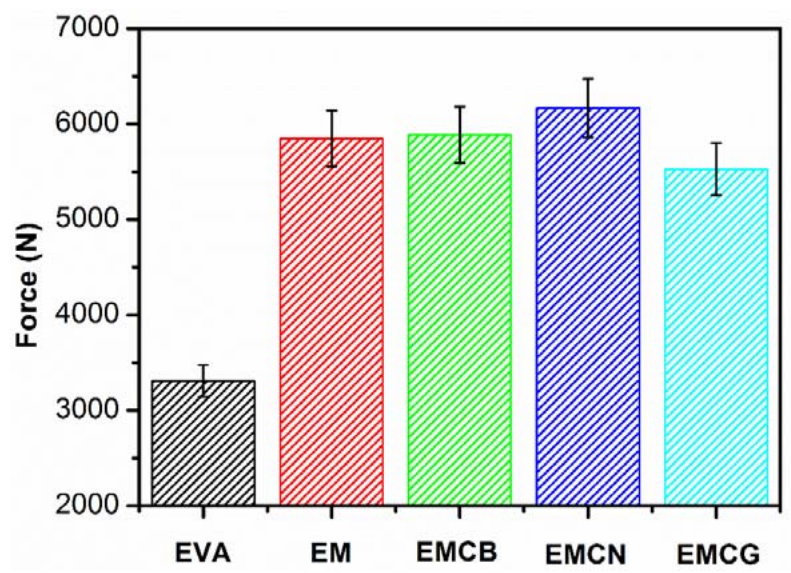

Figure 8. Force of EVA with $\mathrm{MH}$ and different carbon materials after mixing for $15 \mathrm{~min}$ at $180{ }^{\circ} \mathrm{C}$. 
From the above discussion, we concluded that the flame-retardant mechanism of EMC composites was mainly in the condensed phase. The burning process and flame-retardant mechanism can be described as follows [36]. First, the materials were heated to a temperature at which the polymer was melting and bubbles began to form, where thermal degradation occurs, and they grew with the supply of more degradation products by diffusion from the surrounding molten plastic. When the temperature of materials reached ignition temperature, it began to burn. At the same time, during the heating process, $\mathrm{MH}$ was decomposed into magnesium oxide and water, and the released water vapor isolated the flame and diluted the combustible gas in the gas phase. Meanwhile, the accumulated carbon material formed a layer of char by working with magnesium oxide, which was a thermal barrier. This charred layer prevented heat transport of degradation products between the molten polymer and the surface.

\subsection{Mechanical Properties}

In this part, the influence of different fillers on the mechanical properties of EVA composites was investigated. The detailed data are given in Table 5. As can be seen from Table 5, both the tensile strength and elongation at break of EM and EMC materials significantly decreased compared to neat EVA. Compared with EM, the tensile strength and elongation at break of EMCB and EMCG were nearly unchanged, while for EMCN, both tensile strength and elongation at break slightly decreased compared with EM. This indicated that it had not been adversely affected in mechanical properties when few carbon materials were added into the EM system.

Table 5. Mechanical properties of pure EVA and its nanocomposites.

\begin{tabular}{ccc}
\hline Sample & Tensile Strength (MPa) & Elongation at Break (\%) \\
\hline EVA & $23.9 \pm 0.5$ & $1286 \pm 50$ \\
EM & $10.5 \pm 0.3$ & $753 \pm 30$ \\
EMCB & $10.6 \pm 0.2$ & $758 \pm 25$ \\
EMCN & $9.8 \pm 0.2$ & $612 \pm 25$ \\
EMCG & $10.7 \pm 0.3$ & $634 \pm 25$ \\
\hline
\end{tabular}

To understand the dispersion levels of different filler particles in EVA, SEM was used to characterize the freeze-fractured surface microstructure of EVA and its composites. Figure 9 shows SEM micrographs of the freeze-fractured surfaces of EM, EMCB, EMCN, and EMCG. According to the previous studies, the fracture roughness of the polymer nanocomposites reflects the dispersion level and interfacial interaction to some degree [36,39]. It can be observed in Figure 9a that the neat EVA displayed a smooth fracture surface. However, after the MH was mixed with the EVA, the MH particles imaged on the fracture surface of the EVA nanocomposites can be clearly seen in Figures $1 \mathrm{~b}$ and $9 \mathrm{c}-\mathrm{e}$. In addition, it was observed that the surface of EMCN was smoother than other flame-retardant composites, which can explain why the tensile stress value of EMN was lower than other composites. 

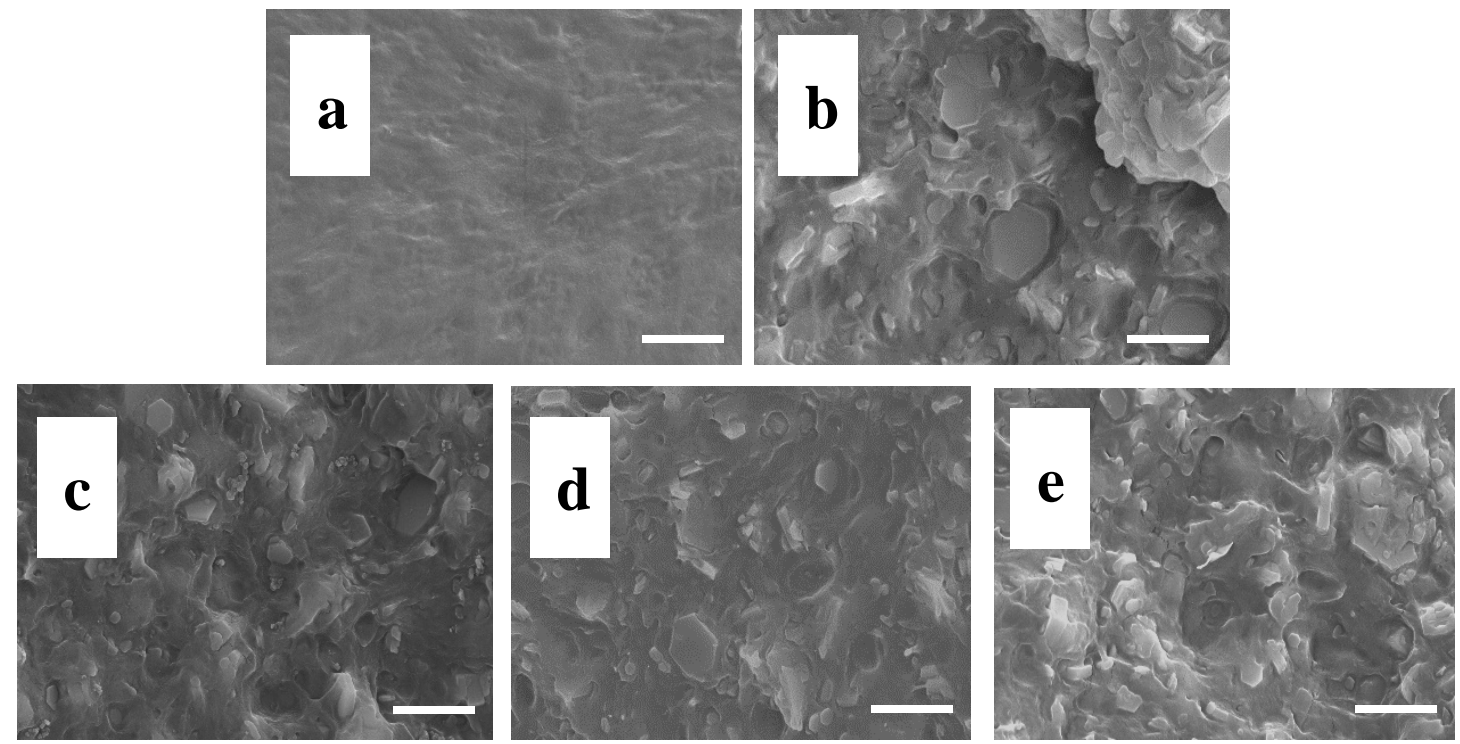

Figure 9. SEM micrographs of the brittle-fractured surface of EVA and its composites: (a) pure EVA, (b) EM, (c) EMCB, (d) EMCN, (e) EMCG. (Scale bar = $2 \mu \mathrm{m}$ ).

To investigate the influence of $\mathrm{MH}$ and carbon materials on the dynamic mechanical behavior of EVA composites, the storage modulus and $\tan \delta$ as the function of temperature were used, shown in Figure 10. From Figure 10a, we can conclude there were no obvious differences in modulus for three samples above $0{ }^{\circ} \mathrm{C}$, while below $0{ }^{\circ} \mathrm{C}$, the storage modulus of EVA composites was higher than that of neat EVA, indicating that EVA composites were more rigid than EVA. This is because the rigid filler imparted stiffness behavior to the filler EVA composites [6]. From Figure 10b, it can be seen that the glass transition temperatures (defined as the temperature at the peak value of $\tan \delta$ ) of EVA composites were all higher than that of pure EVA, which was ascribed to the rigid fillers limiting the mobility of the polymer chains [30].

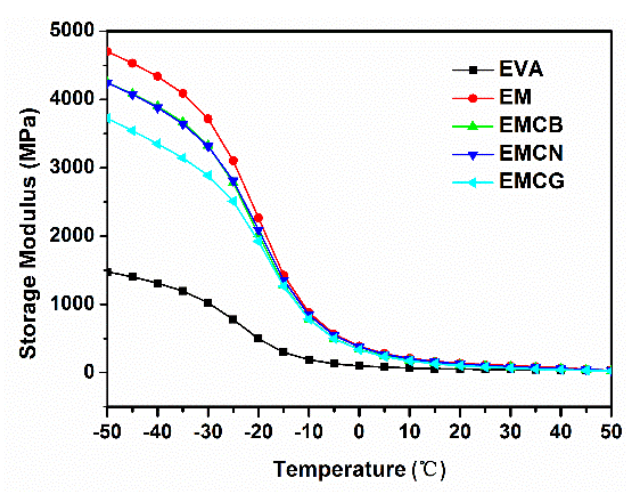

(a)

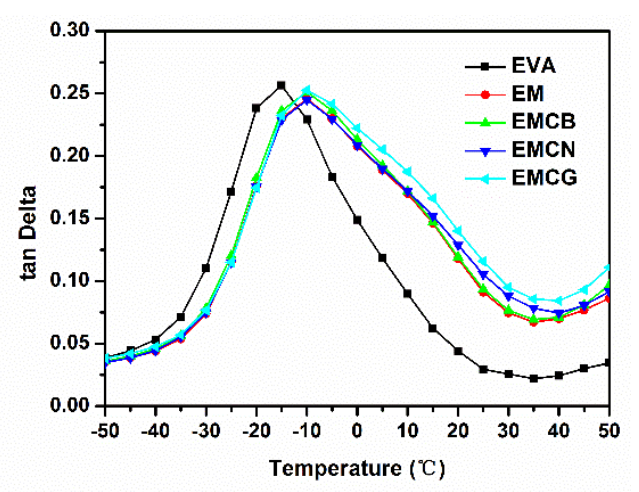

(b)

Figure 10. Temperature dependence of (a) storage modulus and (b) tan $\delta$ of pure EVA and its composites.

\section{Conclusions}

EM with different geometries of carbon materials in EVA matrix was prepared by melt-blending. The TGA results show that EMCN had the best thermal stability. The flame-retardant properties show that the LOI values of EMCB, EMCN, and EMCG were $28.2 \%, 33.3 \%$, and $27.6 \%$, respectively. Meanwhile, all the EM materials with carbon materials passed UL-94 V-0 rating. The combustion behavior results indicate that carbon materials acting as flame-retardant synergistic agents of $\mathrm{MH}$ highly improved the flame retardancy of EVA composites, and the synergistic effects were in the order of one-dimensional CN > zero-dimensional CB > two-dimensional CG. The torque results 
demonstrate that carbon nanotubes with $\mathrm{MH}$ and $\mathrm{CN}$ formed network structures with polymer matrix in the nanocomposites. The flame-retardant mechanism of composites was mainly in the condensed phase. The incorporation of carbon materials did not have a negative effect on the tensile performance of EM composites, and there were also no obvious differences in modulus for all samples above 0 ${ }^{\circ} \mathrm{C}$, while below $0{ }^{\circ} \mathrm{C}$, the storage modulus of EVA composites was higher than that of pure EVA. It was demonstrated that the geometry of carbon material with $\mathrm{MH}$ in EVA matrix plays a key role in structure-property relationships.

Author Contributions: Conceptualization, Z.-Q.L.; Data curation, Z.L., Y.-X.Y., and C.F.; Formal analysis, Z.-Q.L., Z.L., and X.W.; Investigation, Z.-Q.L., Y.-L.Z., X.W., and N.L.; Project administration, Z.-Q.L.; Supervision, D.-Y.W. and L.-J.L.; Writing-original draft, Z.-Q.L.; Writing-review and editing, D.-Y.W., X.W., R.-K.J., and Y.-L.Z.

Funding: This research was partly funded by the Science and Technology of Qinghai Program (No. 2015-HZ-812), the Natural Science Foundation of China (No. U1607104), Amarout II (Marie Curie Action PCOFUND-GA-2011-291803), the Thousand Talents Plan of Qinghai Province of China (2017), and the Ministry of Industry and Information Technology of China (No. P173008047).

Conflicts of Interest: The authors declare no conflict of interest.

\section{References}

1. Fu, M.Z.; Qu, B.J. Synergistic flame retardant mechanism of fumed silica in ethylene-vinyl acetate/magnesium hydroxide blends. Polym. Degrad. Stab. 2004, 85, 633-639. [CrossRef]

2. Isitman, N.A.; Kaynak, C. Nanoclay and carbon nanotubes as potential synergists of an organophosphorus flame-retardant in poly (methyl methacrylate). Polym. Degrad. Stab. 2010, 95, 1523-1532. [CrossRef]

3. Presti, C.; Ferry, L.; Alauzun, J.G.; Dumazert, L.; Gallard, B.; Quantin, J.C.; Lopez Cuesta, J.M.; Mutin, P.H. Functionalized nanodiamond as potential synergist in flame-retardant ethylene vinyl acetate. Diam. Relat. Mater. 2017, 76, 141-149. [CrossRef]

4. Liu, L.; Hu, J.; Zhuo, J.L.; Jiao, C.M.; Chen, X.L.; Li, S.X. Synergistic flame retardant effects between hollow glass microspheres and magnesium hydroxide in ethylene-vinyl acetate composites. Polym. Degrad. Stab. 2014, 104, 87-94. [CrossRef]

5. Wu, X.F.; Wang, L.C.; Wu, C.; Yu, J.H.; Xie, L.Y.; Wang, G.L.; Jiang, P.K. Influence of char residues on flammability of EVA/EG, EVA/NG and EVA/GO composites. Polym. Degrad. Stab. 2012, 97, 54-63. [CrossRef]

6. Klapiszewski, Ł.; Tomaszewska, J.; Skórczewska, K.; Jesionowski, T. Preparation and Characterization of Eco-Friendly $\mathrm{Mg}(\mathrm{OH})_{2} /$ Lignin Hybrid Material and Its Use as a Functional Filler for Poly(Vinyl Chloride). Polymers 2017, 9, 258. [CrossRef]

7. Maira, B.; Chammingkwan, P.; Terano, M.; Taniike, T. New Reactor Granule Technology for Highly Filled Nanocomposites: Effective Flame Retardation of Polypropylene/Magnesium Hydroxide Nanocomposites. Macromol. Mater. Eng. 2015, 300, 679-683. [CrossRef]

8. Zaghloul, M.M.Y.; Zaghloul, M.M.Y. Influence of flame retardant magnesium hydroxide on the mechanical properties of high density polyethylene composites. J. Reinf. Plast. Compos. 2017, 36, 1802-1816. [CrossRef]

9. Suihkonen, R.; Nevalainen, K.; Orell, O.; Honkanen, M.; Tang, L.C.; Zhang, H.; Zhang, Z.; Vuorinen, J. Performance of epoxy filled with nano- and micro-sized Magnesium hydroxide. J. Mater. Sci. 2012, 47, 1480-1488. [CrossRef]

10. Liu, J.C.; Peng, S.G.; Zhang, Y.B.; Chang, H.B.; Yu, Z.L.; Pan, B.L.; Lu, C.; Ma, J.Y.; Niu, Q.S. Influence of microencapsulated red phosphorus on the flame retardancy of high impact polystyrene/magnesium hydroxide composite and its mode of action. Polym. Degrad. Stab. 2015, 121, 208-221. [CrossRef]

11. Durin, F.A.; Ferry, L.; Lopez, C.J.M.; Crespy, A. Magnesium hydroxide/zinc borate/talc compositions as flame-retardants in EVA copolymer. Polym. Int. 2000, 49, 1101-1105. [CrossRef]

12. Yen, Y.Y.; Wang, H.T.; Guo, W.J. Synergistic flame retardant effect of metal hydroxide and nanoclay in EVA composites. Polym. Degrad. Stab. 2012, 97, 863-869. [CrossRef]

13. Riva, A.; Zanetti, M.; Braglia, M.; Camino, G.; Falqui, L. Thermal degradation and rheological behaviour of EVA/montmorillonite nanocomposites. Polym. Degrad. Stab. 2002, 77, 299-304. [CrossRef] 
14. Zhang, G.B.; Ding, P.; Zhang, M.; Qu, B.J. Synergistic effects of layered double hydroxide with hyperfine magnesium hydroxide in halogen-free flame retardant EVA/HFMH/LDH nanocomposites. Polym. Degrad. Stab. 2007, 92, 1715-1720. [CrossRef]

15. Dittrich, B.; Wartig, K.A.; Mülhaupt, R.; Schartel, B. Flame-Retardancy Properties of Intumescent Ammonium Poly(Phosphate) and Mineral Filler Magnesium Hydroxide in Combination with Graphene. Polymers 2014, 6, 2875-2895. [CrossRef]

16. Dittrich, B.; Wartig, K.A.; Hofmann, D.; Mülhaupt, R.; Schartel, B. Flame retardancy through carbon nanomaterials: Carbon black, multiwall nanotubes, expanded graphite, multi-layer graphene and graphene in polypropylene. Polym. Degrad. Stab. 2013, 98, 1495-1505. [CrossRef]

17. Wang, X.; Kalali, E.N.; Wan, J.T.; Wang, D.Y. Carbon-family materials for flame retardant polymeric materials. Prog. Polym. Sci. 2017, 69, 22-46. [CrossRef]

18. Mamani, A.; Ebrahimi, M.; Ataeefard, M. A study on mechanical, thermal and flame retardant properties of epoxy/expandable graphite composites. Pigment Resin Technol. 2017, 46, 131-138. [CrossRef]

19. Caschera, D.; Toro, R.G.; Federici, F.; Riccucci, C.; Ingo, G.M.; Gigli, G.; Cortese, B. Flame retardant properties of plasma pre-treated/diamond-like carbon (DLC) coated cotton fabrics. Cellulose 2015, 22, 2797-2809. [CrossRef]

20. Kashiwagi, T.; Grulke, E.; Hilding, J.; Harris, R.; Awad, W.; Douglas, J. Thermal Degradation and Flammability Properties of Poly(propylene)/Carbon Nanotube Composites. Macromol. Rapid Commun. 2002, 23, 761-765. [CrossRef]

21. Wen, X.; Wang, Y.J.; Gong, J.; Liu, J.; Tian, N.N.; Wang, Y.H.; Jiang, Z.W.; Qiu, J.; Tang, T. Thermal and flammability properties of polypropylene/carbon black nanocomposites. Polym. Degrad. Stab. 2012, 97, 793-801. [CrossRef]

22. Yang, H.F.; Gong, J.; Wen, X.; Xue, J.; Chen, Q.; Jiang, Z.W.; Tian, N.N.; Tang, T. Effect of carbon black on improving thermal stability, flame retardancy and electrical conductivity of polypropylene/carbon fiber composites. Compos. Sci. Technol. 2015, 113, 31-37. [CrossRef]

23. Novoselov, K.S.; Geim, A.K.; Morozov, S.V.; Jiang, D.; Zhang, Y.; Dubonos, S.V.; Grigorieva, I.V.; Firsov, A.A. Electric Field Effect in Atomically Thin Carbon Films. Science 2004, 306, 666-669. [CrossRef] [PubMed]

24. Liu, S.; Fang, Z.P.; Yan, H.Q.; Chevali, V.S. Synergistic flame retardancy effect of graphene nanosheets and traditional retardants on epoxy resin. Compos. Part A Appl. Sci. Manuf. 2016, 89, 26-32. [CrossRef]

25. Liu, S.; Yan, H.Q.; Fang, Z.P.; Wang, H. Effect of graphene nanosheets on morphology, thermal stability and flame retardancy of epoxy resin. Compos. Sci. Technol. 2014, 90, 40-47. [CrossRef]

26. Hummers, W.S.; Offeman, R.E. Preparation of Graphitic Oxide. J. Am. Chem. Soc. 1958, 80, 1339. [CrossRef]

27. Chen, J.; Yao, B.W.; Li, C.; Shi, G.Q. An improved Hummers method for eco-friendly synthesis of graphene oxide. Carbon 2013, 64, 225-229. [CrossRef]

28. Li, Z.; González, A.J.; Heeralal, V.B.; Wang, D.Y. Covalent assembly of MCM-41 nanospheres on graphene oxide for improving fire retardancy and mechanical property of epoxy resin. Compos. Part B Eng. 2018, 138, 101-112. [CrossRef]

29. Yu, L.; Chen, L.; Dong, L.P.; Li, L.J.; Wang, Y.Z. Organic-inorganic hybrid flame retardant: Preparation, characterization and application in EVA. RSC Adv. 2014, 4, 17812-17821. [CrossRef]

30. Zhou, K.Q.; Tang, G.; Jiang, S.H.; Gui, Z.; Hu, Y. Combination effect of $\mathrm{MoS}_{2}$ with aluminum hypophosphite in flame retardant ethylene-vinyl acetate composites. RSC Adv. 2016, 6, 37672-37680. [CrossRef]

31. Kashiwagi, T.; Du, F.M.; Douglas, J.F.; Winey, K.I.; Harris, R.H., Jr.; Shields, J.R. Nanoparticle networks reduce the flammability of polymer nanocomposites. Nat. Mater. 2005, 4, 928-933. [CrossRef] [PubMed]

32. Li, Z.; Liu, L.J.; Jimenez Gonzalez, A.; Wang, D.Y. Bioinspired polydopamine-induced assembly of ultrafine $\mathrm{Fe}(\mathrm{OH})_{3}$ nanoparticles on halloysite toward highly efficient fire retardancy of epoxy resin via an action of interfacial catalysis. Polym. Chem. 2017, 8, 3926-3936. [CrossRef]

33. Jian, R.K.; Wang, P.; Xia, L.; Yu, X.Q.; Zheng, X.L.; Shao, Z.B. Low-flammability epoxy resins with improved mechanical properties using a Lewis base based on phosphaphenanthrene and 2-aminothiazole. J. Mater. Sci. 2017, 52, 9907-9921. [CrossRef]

34. Jian, R.K.; Wang, P.; Duan, W.S.; Wang, J.S.; Zheng, X.L.; Weng, J.B. Synthesis of a Novel P/N/S-Containing Flame Retardant and Its Application in Epoxy Resin: Thermal Property, Flame Retardance, and Pyrolysis Behavior. Ind. Eng. Chem. Res. 2016, 55, 11520-11527. [CrossRef] 
35. Kashiwagi, T.; Mu, M.F.; Winey, K.; Cipriano, B.; Raghavan, S.R.; Pack, S.; Rafailovich, M.; Yang, Y.; Grulke, E.; Shields, J.; et al. Relation between the viscoelastic and flammability properties of polymer nanocomposites. Polymer 2008, 49, 4358-4368. [CrossRef]

36. Kashiwagi, T.; Fagan, J.; Douglas, J.F.; Yamamoto, K.; Heckert, A.N.; Leigh, S.D.; Obrzut, J.; Du, F.M.; Lin-Gibson, S.; Mu, M.F.; et al. Relationship between dispersion metric and properties of PMMA/SWNT nanocomposites. Polymer 2007, 48, 4855-4866. [CrossRef]

37. Hidalgo, J.; Jiménez-Morales, A.; Torralba, J.M. Torque rheology of zircon feedstocks for powder injection moulding. J. Eur. Ceram. Soc. 2012, 32, 4063-4072. [CrossRef]

38. Ye, L.; Wu, Q.H.; Qu, B.J. Synergistic effects and mechanism of multiwalled carbon nanotubes with magnesium hydroxide in halogen-free flame retardant EVA/MH/MWNT nanocomposites. Polym. Degrad. Stab. 2009, 94, 751-756. [CrossRef]

39. Wang, D.; Song, L.; Zhou, K.Q.; Yu, X.J.; Hu, Y.; Wang, J. Anomalous nano-barrier effects of ultrathin molybdenum disulfide nanosheets for improving the flame retardance of polymer nanocomposites. J. Mater. Chem. A 2015, 3, 14307-14317. [CrossRef]

(C) 2018 by the authors. Licensee MDPI, Basel, Switzerland. This article is an open access article distributed under the terms and conditions of the Creative Commons Attribution (CC BY) license (http://creativecommons.org/licenses/by/4.0/). 